\title{
Emulsion for Injection/Infusion Dosage Form
}

National Cancer Institute

\section{Source}

National Cancer Institute. Emulsion for Injection/Infusion Dosage Form. NCI Thesaurus.

Code C149481.

Liquid sterile single-dose or multidose preparation consisting of an emulsion intended for administration by injection or infusion. 